\title{
Lysosomal Fusion Dysfunction as a Unifying Hypothesis for Alzheimer's Disease Pathology
}

\author{
Kristen E. Funk and Jeff Kuret \\ Department of Molecular and Cellular Biochemistry, The Ohio State University College of Medicine, Columbus, OH 43210, USA \\ Correspondence should be addressed to Kristen E. Funk, kristenefunk@gmail.com and Jeff Kuret, kuret.3@osu.edu
}

Received 2 June 2012; Revised 1 August 2012; Accepted 2 August 2012

Academic Editor: Wiep Scheper

Copyright ( $\odot 2012$ K. E. Funk and J. Kuret. This is an open access article distributed under the Creative Commons Attribution License, which permits unrestricted use, distribution, and reproduction in any medium, provided the original work is properly cited.

\begin{abstract}
Alzheimer's disease is characterized pathologically by extracellular senile plaques, intracellular neurofibrillary tangles, and granulovacuolar degeneration. It has been debated whether these hallmark lesions are markers or mediators of disease progression, and numerous paradigms have been proposed to explain the appearance of each lesion individually. However, the unfaltering predictability of these lesions suggests a single pathological nidus central to disease onset and progression. One of the earliest pathologies observed in Alzheimer's disease is endocytic dysfunction. Here we review the recent literature of endocytic dysfunction with particular focus on disrupted lysosomal fusion and propose it as a unifying hypothesis for the three most-studied lesions of Alzheimer's disease.
\end{abstract}

\section{Introduction}

Alzheimer's disease (AD) is defined by the appearance of pathological hallmarks within specific areas of the brain, including amyloid plaques, composed of extracellular amyloid beta $(\mathrm{A} \beta)$ peptide [1] and neurofibrillary tangles (NFTs), composed of intracellular aggregates of the microtubuleassociated protein tau [2]. Definitive diagnosis of AD is made at autopsy on the basis of these defining lesions, which have a well-documented but incompletely understood connection to disease. Although it has been debated whether these lesions are mediators of disease, they have clear correlation to disease progression and are useful as clues to understanding the pathological processes accompanying neurodegeneration. Additional hallmarks of $\mathrm{AD}$ include granulovacuolar degeneration (GVD), characterized morphologically as intracellular double membrane-bound organelles harboring a dense core and extracellular tau detectable in the cerebrospinal fluid (CSF) $[3,4]$. Although the molecular mechanisms for individual pathological lesions have been proposed [5-7], a unifying hypothesis that rationalizes the appearance of all hallmarks of disease has been elusive. Here we review recent studies involving the intracellular vesicular pathways and their connection to the hallmark lesions of
AD. We propose that vesicle trafficking dysfunction, and more specifically a failure in lysosomal fusion, may be the nidus of both defining lesions of $\mathrm{AD}$ as well as of GVD and extracellular tau, thus providing a unifying hypothesis for disease pathology.

\section{Vesicle Trafficking Dysfunction}

Intracellular vesicle trafficking pathways form an interconnected, dynamic system for transfer of cellular constituents within the cell and between intracellular and extracellular compartments [8] (Figure 1). Cell surface proteins can enter the system through endocytosis. For example, the epidermal growth factor receptor is endocytosed and incorporated into early endosomes after binding its ligand and becoming ubiquitylated $[9,10]$. Endocytosed material can then be budded off into recycling endosomes for exocytic release or incorporated into intralumenal vesicles of the multivesicular body (MVB) by the sequential activity of the endosomal sorting complexes required for transport (ESCRTs) [11-13]. Intralumenal vesicles and their contents may also be released as exosomes by fusion of the outer membrane of the MVB with the plasma membrane $[14,15]$. The endocytic pathway merges with the macroautophagic (hereafter referred to as 


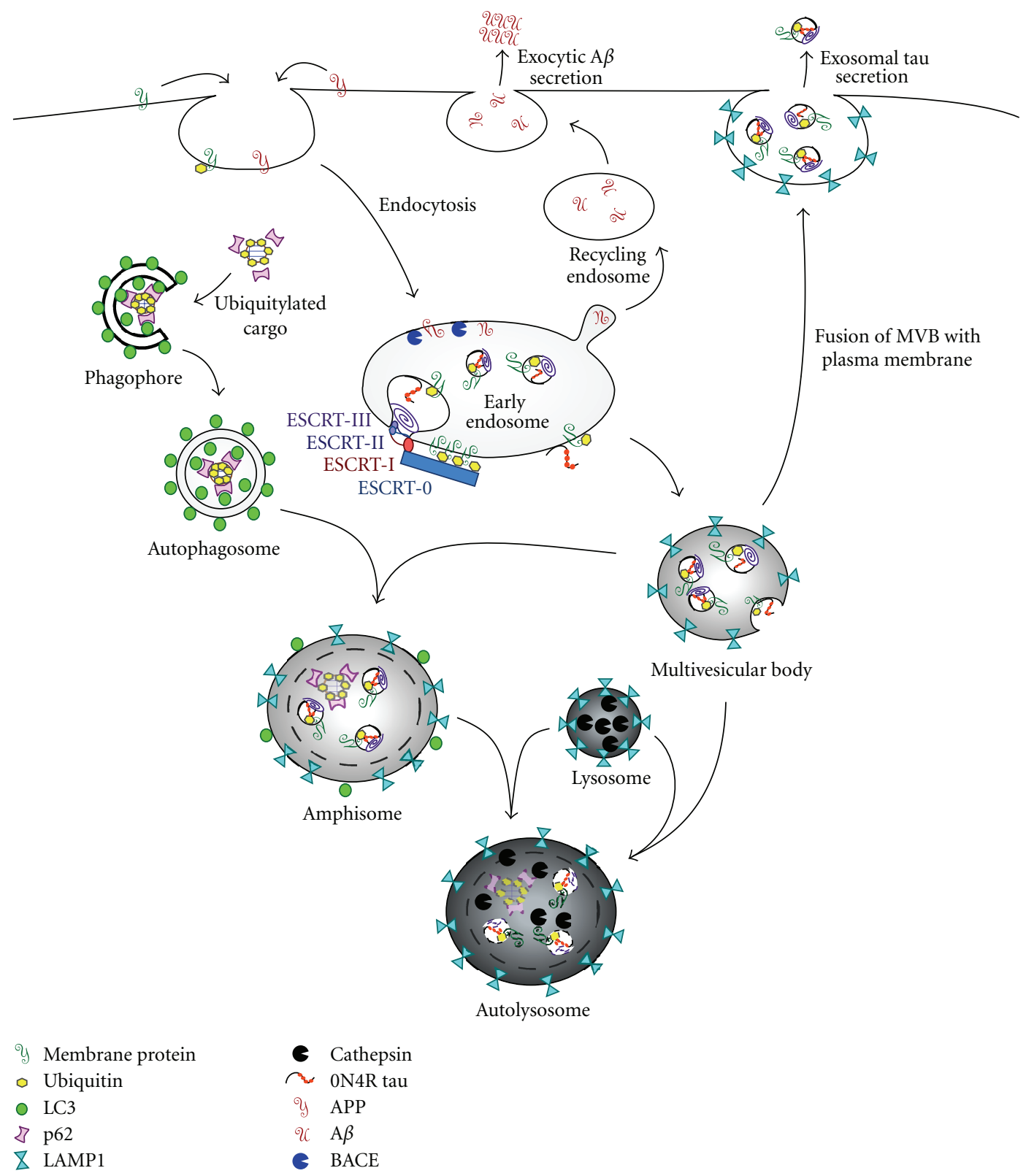

FIGURE 1: Intracellular vesicular trafficking pathways. Endocytosed surface proteins, such as APP, are delivered to the endosomal system by internalization. Internalized membrane proteins can be sorted into intralumenal vesicles of the MVB by sequential activity of ESCRTs 0, I, II, and III or delivered to the extracellular environment by the recycling endosome. Mature MVBs fuse with either the autophagosome of the autophagic pathway to form the amphisome or directly with the lysosome, which donates degradative hydrolases, creating the autolysosome where complete degradation of the sequestered material occurs. Alternatively, the multivesicular body can fuse with the plasma membrane, resulting in the exosomal secretion of the intralumenal vesicles and their internalized cargo.

simply autophagic) pathway at either the early endosome or MVB stage [16]. In the autophagic pathway, target proteins are polyubiquitylated, fostering the binding of p62, the autophagic protein microtubule-associated protein 1 light chain 3 (LC3) [17], and the assembly of the autophagic membrane around the ubiquitylated cargo to form the autophagosome [18]. The autophagosome can then fuse with the lysosome directly or with the MVB to form the amphisome, a slightly acidic hybrid organelle. The amphisome also can fuse with the lysosome to form the autolysosome, a caustic organelle that degrades the enclosed proteins and organelles $[19,20]$.

The dynamic nature of this system is difficult to capture in fixed postmortem tissue; however, there are several lines of evidence suggesting that changes in pathway flux are among the earliest pathologies observed in $\mathrm{AD}$, preceding clinical symptoms of AD, intracellular NFT formation, and extracellular amyloid deposition [21, 22]. First, expression profiling during the progression of $\mathrm{AD}$ has revealed significant upregulation of effector genes of the early endosome 
(including rab4 and rab5), the late endosome ( $\mathrm{rab} 7$ ), and the exocytic pathway (rab27) [23-25]. These expression changes are consistent with morphological phenotypes observed in AD. For example, overexpression of rab5 causes enlarged endosomes, one of the earliest pathological alterations observed in $\mathrm{AD}$ [26]. Rab7 upregulation is found in vulnerable hippocampal basal forebrain regions but not in relatively spared striatum and cerebellum in mild cognitive impairment and $\mathrm{AD}[24,27]$. Second, the accumulation of $\mathrm{A} \beta$ and tau protein and the appearance of GVD bodies correlates with changes in trafficking pathways. These data are summarized below.

2.1. A $\beta$ Accumulation. Full-length amyloid precursor protein (APP) is a transmembrane protein with an incompletely understood function. $A \beta$, the secreted peptide that aggregates to form senile plaques, is cleaved from APP by sequential activities of $\beta$ - and $\gamma$-secretase enzymes [28]. $\beta$ secretase activity is catalyzed by multiple enzymes including $\mathrm{BACE} 1$, which contributes strongly to $\mathrm{A} \beta$ peptide production, BACE2, which is a BACE1 structural homolog, and lysosomal enzyme cathepsin B $[29,30]$. Following $\beta$ cleavage, $\gamma$-secretase-mediated cleavage takes place within the transmembrane domain, yielding primarily $40\left(\mathrm{~A} \beta_{40}\right)$ or $42\left(\mathrm{~A} \beta_{42}\right)$ amino acid peptides [28]. $\mathrm{A} \beta_{40}$ is continuously and abundantly produced in both healthy and $\mathrm{AD}$-affected brain, whereas $A \beta_{42}$ is produced at lower levels in healthy individuals but is increased by familial AD (fAD-) causing mutations [31]. In general, CSF $A \beta_{42}$, but not $A \beta_{40}$, can serve as a surrogate biomarker for $A \beta$ deposition in the brain $[4,32]$.

Observations in both human tissue and cell culture implicate the endocytic pathway in $\mathrm{A} \beta$ production [22, 33-37]. AD-related endocytic dysfunction coincides with the detection of $\mathrm{A} \beta$ within endosomal compartments and autophagic vacuoles that collect within dystrophic neurites with the initial rise in soluble $\mathrm{A} \beta$ peptides $[35,36,38]$. The presence of $\mathrm{A} \beta$ in early endosomes also is consistent with the colocalization of APP and BACE1 within the same early endocytic compartments [39-42] and the degradation of BACE within the endosomal-lysosomal system [43]. One study suggests that internalized $A \beta$ can aggregate within the cell and disrupt the vesicular membrane, thus contributing to its pathologic effect [44]. Intracellular trafficking of proteins involves a series of cytosolic factors, some of which are implicated in the regulation of APP trafficking and $A \beta$ generation. For example, rab6, a protein implicated in membrane budding and clathrin, which mediates the internalization of APP from the cell surface, affect APP processing $[45,46]$. Altogether, these data support a relationship between endocytic pathway dysfunction and the amyloidogenic processing of APP.

Rare disease-causing mutations have been discovered within the $A P P$ gene that result in increased $\mathrm{A} \beta$ production, $\mathrm{A} \beta 42$ : $\mathrm{A} \beta 40$ ratio, or $\mathrm{A} \beta$ aggregation rate [47]. More common, although still rare, are autosomal dominant mutations within the PSEN1 gene encoding presenilin 1(PS1), a transmembrane protein that acts as the catalytic subunit of the $\gamma$-secretase complex $[48,49]$. This complex is located in the endoplasmic reticulum, transgolgi network, and endocytic compartments $[50,51]$. The precise mechanism through which PS1 mutations drive AD is unclear, but they can cause aberrant processing of APP leading to increased $A \beta 42$ : $A \beta 40$ ratio $[52,53]$. Further studies have revealed that familial AD-linked PS1 mutations significantly reduce budding from the endoplasmic reticulum and golgi, thereby decreasing delivery of APP to the cell surface [54]. This suggests that familial $A D$-linked PS1 variants increase $A \beta$ production by decreasing intracellular transport of APP, thus prolonging the availability of APP for cleavage by $\beta$ and $\gamma$-secretases within the golgi. PS1 may regulate protein trafficking through its interaction with several cytosolic factors involved in the regulation of vesicular transport, such as rab11, rab6, and rab regulators [55-57]. Other data have ascribed the pathogenic effects of PS1 mutations to its role in facilitating maturation and targeting of a subunit of the vacuolar ATPase to the lysosome, which is essential for lysosomal acidification, protease activation, and degradation of lysosomal substrates [58]. This supports the impaired lysosomal fusion hypothesis, in that Bafilomycin A, a vacuolar ATPase inhibitor, is known to impair fusion of the lysosome with other membrane-bound vesicles [59]. However, recently the role of PS1 in the maturation of the vacuolar ATPase has been challenged, instead attributing lysosomal dysfunction in PS1-mutant cells to changes in gene expression associated with lysosome biogenesis [60] or alteration in lysosomal calcium storage and release [61]. Calcium storage and release have been proposed to regulate vesicular fusion [62], and in fact, is dependent on protonmotive force [63]. Therefore differentiating between these potential mechanisms may be challenging. In the future it will be important to determine the actual role of PS1 in the adult brain in order to parse these differences. Because $\mathrm{A} \beta$ is both generated and degraded via the endocytic and autophagic pathways [38], impaired lysosomal clearance could mediate PS1-dependent increases in A $\beta$ concentration.

The identification of genetic mutations that cause earlyonset $\mathrm{AD}$ has lead to a greater understanding of the molecular mechanisms of disease; however, these mutations account for only a small fraction of cases. Rather, the majority of cases are sporadic with multiple susceptibility genes contributing incremental risk of developing disease $[64,65]$. The role of each in $\mathrm{AD}$ pathogenesis will require further investigation; however, several of these susceptibility genes have known functions within or adjacent to the endocytic pathway. The strongest risk locus identified thus far is the gene that encodes apolipoprotein $\mathrm{E}(A P O E)$, a protein component of lipoprotein particles that bind to cell surface receptors with function in lipid transport, $A \beta$ trafficking, synaptic function, immune regulation, and intracellular signaling $[66,67]$. A second risk-conferring gene is $S O R L 1$, a receptor that participates in trafficking vesicles from the cell surface to the Golgi-endoplasmic reticulum [68]. Other new risk genes, including BIN1 [69] and PICALM [64], are involved in clathrin-mediated endocytosis. Clusterin, also known as apolipoprotein J, has also been identified to increase risk of $\mathrm{AD}[64,65]$ and is hypothesized to act as an extracellular 
chaperone that influences $\mathrm{A} \beta$-aggregation and receptormediated $\mathrm{A} \beta$ clearance by endocytosis $[70,71]$. Although each of these genes confers only incremental risk, together they highlight the intracellular vesicle trafficking in the molecular pathogenesis of sporadic AD.

\subsection{Tau}

2.2.1. Extracellular Tau. The appearance of tau and phospho-tau (p-tau) in CSF has been assumed to result from the passive release of tau from dying neurons [4]. However, recently it was shown that tau may be actively secreted into the extracellular compartment, where it is positioned to participate in the transmission of neurofibrillary pathology $[72,73]$. Exosome-mediated release is considered a common, yet unconventional, mechanism responsible for the secretion of other aggregation-prone proteins including $\alpha$-synuclein [74], prion protein [75], $A \beta[76]$, and tau [77]. Secreted tau associates with both typical exosomal proteins, such as Alix and with proteins involved in tau misprocessing and $\mathrm{AD}$ pathogenesis, such as $\mathrm{A} \beta$, presenilins, and fyn kinase [77]. Furthermore, exosomal tau is phosphorylated at Thr181, accordant with CSF data [77]. Somewhat surprisingly, the greatest amount of exosomal tau was found in early AD, with the greatest being in Braak stage 3, progressively less so in later stages of $\mathrm{AD}$ when neuronal death is rampant and absent from non-AD controls diagnosed with nontauopathic dementias [77]. Because there is relatively little neurofibrillary degeneration at this early stage [78], the elevation of ptau in AD CSF is not due to passive, nonspecific tau release consequent to neuronal death. Rather, these data highlight the vesicle trafficking pathway involved in tau processing and secretion.

A lysosomal fusion defect may account for the diseaserelated detection of tau in the CSF. The p-tau that accumulates where dendritic microtubules are being lost in dendrites is largely vesicle associated, and some of these vesicles are amphisome like, harboring both endocytic (fyn) and autophagic (LC3) markers [79]. Fyn activation during signal transduction typically causes the oligomerization and endocytosis of downstream elements [80] and targets at least some oligomerized targets of fyn phosphorylation to exosomes $[81,82]$. Although in normal autophagy, LC3 is rarely exocytosed [83], the inability of the autophagic vesicle to fuse with the lysosome may alternatively shuttle vesicles towards the exosomal pathway (Figure 1). This exosomal secretion of tau corroborates the recent suggestion that interneuronal transfer of tau may be an important aspect of pathogenesis and account for the stereotypic neurofibrillary lesion progression [84-88]. Furthermore, this is consistent with recent evidence gathered from the lysosomal storage disorder, Niemann-Pick type $\mathrm{C}$ disease, in which exosomal release of cholesterol may serve as a cellular mechanism to partially bypass the traffic block that results in its toxic accumulation within the lysosome [89]. Altogether, although tau lacks the usual features of secreted proteins, such as an $\mathrm{N}$-terminal hydrophobic "leader" sequence and lipidation sites, data suggests that tau is secreted, though it may be low in healthy neurons such as when the lysosomal system is functioning normally [73].

2.2.2. Intracellular Tau. Failure of the lysosome to efficiently fuse with membrane-bound organelles and degrade encaptured proteins of the endocytic and autophagic pathways may also affect the intracellular concentrations of tau. Consistent with lysosome-mediated effects on tau levels, soluble tau is a substrate for lysosomal proteases such as cathepsin $\mathrm{D}$ in vitro and in cultured cells [90,91], and inhibition of lysosome function with chloroquine can increase bulk tau levels [92]. Moreover, tau immunoreactivity associates with lysosomal protease cathepsin $\mathrm{B}$ in $\mathrm{AD}$ brain [93] and neuronal lysosomes in sections of both $\mathrm{AD}$ and control brain [94]. Because tau concentration modulates tau aggregation at both nucleation and extension steps $[95,96]$, it is a direct modulator of neurofibrillary lesion formation.

Tau can be delivered to lysosomes through multiple pathways. First among these is autophagy, which can mediate turnover of tau phosphorylated on KXGS motifs in the microtubule repeat region $[97,98]$. Evidence suggests that ptau is less susceptible to proteasomal degradation mediated by hsp90 [99]. Therefore, under these conditions, failure of lysosome degradation could lead to elevated p-tau levels. Second, tau contains two sequence motifs for chaperonemediated autophagy [99], a pathway that relies on hsc70 to target substrates directly to the lysosome. In a cellular model of tauopathy, the chaperone-mediated autophagy machinery and associated recognition motifs on tau protein enable the generation of tau fragments by lysosomal proteases [99]. These fragments have a higher propensity to form $\beta$-sheet aggregates that, once nucleated, can seed the aggregation of full length tau [100]. Because these fragments are generated via chaperone-mediated autophagy, they can be produced even if lysosomal fusion stalls so long as lysosomal proteases remain functional. Overall, the failure of the lysosomal pathway to efficiently clear intracellular tau may foster its pathological aggregation not only by increasing cytosolic concentrations but by generating aggregation-nucleating fragments as well.

Endocytic abnormalities may be involved in non-AD tauopathies, independent from $\mathrm{A} \beta$ deposition. Tau is redistributed to microtubule-poor regions of the cell when it is present in excess of available microtubule-binding capacity, which can result from overexpression, mutation, or posttranslational modifications (PTMs) that limit taumicrotubule binding $[79,101]$. Since tau has been shown to modulate the activity of microtubule-associated motor proteins that mediate dendritic transport $[102,103]$, it is possible that toxicity resulting from tau accumulation at localized dendritic loci may have relevance to pathogenesis of non-AD tauopathies. Moreover, this toxic, vesicle-associated tau accumulates selectively in microtubule-poor segments containing organized microtubule bundles, suggesting that its accumulation is both the cause and consequence of localized microtubule destabilization [79]. Furthermore, neuropathological examination of Niemann-Pick-type C disease has revealed tau-laden NFTs without accompanying amyloid pathology [104]. Although the pathogenesis of the 
NFTs in Niemann-Pick-type C disease is not clear, the presence of dystrophic axonal swellings suggest cytoskeletal abnormalities [104]. This indicates that under certain conditions, lysosomal dysfunction alone can ultimately lead to NFT formation in the absence of $A \beta$ deposits.

2.2.3. Mechanisms of Tau Regulation. The mechanisms regulating tau secretion through the intracellular vesicular trafficking pathways are unknown but may involve those also responsible for modulating pathological and normal tau biology, including alternative splicing and PTMs. Tau protein is encoded by a single gene comprising 16 exons $[105,106]$. Exons 2, 3, and 10 undergo alternative splicing; however, exon 3 is expressed only in the presence of exon 2 , thus yielding 6 isoforms. Depending on the presence or absence of the protein sequence encoded by exon 10 (e10), tau isoforms are called 4R (with e10) or 3R (without e10), referring to the number of imperfect microtubule-binding repeats. Similarly, tau isoforms are called $0 \mathrm{~N}$ (without Nterminal inserts), $1 \mathrm{~N}$ (with one $\mathrm{N}$-terminal insert, encoded by exon 2), or $2 \mathrm{~N}$ (with two $\mathrm{N}$-terminal inserts, encoded by exons 2 and 3). E10 has received relatively more attention than either $\mathrm{N}$-terminal inserts (e2 and e3) due to its role in microtubule binding and self-aggregation. However, recent evidence suggests that while extracellular secretion of tau requires the presence of an unknown element in the $\mathrm{N}$ terminal domain [73], e2 specifically inhibits this secretion [72]. This agrees with known functions of the $\mathrm{N}$-terminus of tau to mediate association with the plasma membrane and perimembranous structures [107].

In conjunction with the inclusion or exclusion of e10, the affinity of tau for microtubules is regulated by its phosphorylation at sites in and around the microtubule-binding repeat region, with certain sites having more acute affects on the protein than others [108-110]. Exosomal fractions of conditioned media of human neuroblastoma cells are enriched in p-tau species associated with neurodegeneration [77]. Quantitative analysis has identified four epitopes within the proline-rich domain of tau that are most strongly enriched in secreted tau compared with intracellular tau [77]. These epitopes include AT270, AT8, AT100, and AT180, which correspond to phosphorylation at Thr-181, Ser-198 and Ser-202, Ser-210 and Thr-212, and Thr-231, respectively. Significantly, epitope AT270 (corresponding to phosphorylated Thr-181) is the epitope most highly enriched in secreted tau and is also an established biomarker for CSFbased diagnostics for early-stage AD [77, 111]. The potential role of phosphorylation as a regulator of tau secretion is corroborated by CSF biomarker data gathered from patients with acute brain injury, which at the cellular level involves axonal injury [112]. Importantly, total tau, but not p-tau, increases following acute brain injury [4], suggesting that while total tau may be released as a result of cellular damage and death, PTMs may actively regulate tau secretion.

As many as 30 different phosphorylation sites have been identified on tau [113], and although phosphorylation is the most comprehensively studied of the tau PTMs, filamentous tau is known to be extensively modified by several PTMs, including lysine-directed ubiquitylation [114]. We and others have identified at least three sites of ubiquitylation on tau [115-117]. Although most well known for its role in proteasomal degradation of proteins, ubiquitin is also the best known signal for endocytic sorting [118]. As a general rule, targeting to the proteasome requires attachment of a chain of at least four ubiquitins [119], whereas targeting to the endocytic pathway requires only a single ubiquitin or a short chain of two or three ubiquitins [118]. These ubiquitins are recognized by the ESCRT machinery, which sort the ubiquitylated cargo and direct it towards its destined pathway $[12,13]$. In addition to the influence that PTMs exert on tau function individually, it is thought that various modifications may cooperate and compete in a coordinated fashion. For example, recently two modifications have been identified that are also lysine directed: acetylation $[120,121]$ and methylation [117]. Because these modifications both directly compete with ubiquitin for lysine site occupancy, there is potential for acetylation and methylation to directly affect the rate of turnover of tau protein and its motility through the endocytic pathway. Furthermore, in other biochemical pathways, such as histone-regulated processes, there is precedent for PTMs, including acetylation and methylation, to indirectly affect neighboring site modification, such as phosphorylation [122], though the potential for this type of modification crosstalk to be occurring in tau protein and its effect on tau metabolism has yet to be examined.

2.3. GVD Bodies. Evidence of dysfunctional endocytic/ autophagic pathway in AD extends to GVD. GVD body load increases with disease severity and episodic memory decline $[3,123,124]$. GVD body ultrastructure has been extensively studied, revealing an electron-dense core with coarse or vesicular morphology surrounded by a double-layered membrane [125]. Because of the two-layered membrane, it has long been hypothesized that these lesions are of autophagic origin [125]. Recent work by us and others has implicated the endocytic pathway in the formation of GVD bodies due to strong immunoreactivity of CHMP2B, a component of ESCRT-III, in the GVD body core [126, 127]. This work also suggests a failure of the MVB to fuse with the lysosome [126], which could account for an accumulation of autophagic intermediates [128] and an increased size and density of the MVB [10]. We hypothesize that consequently, flux is routed to the autophagic pathway, which results in the accumulation of abnormally large amphisome-like intermediates owing to the same lysosomal fusion defect combined with mTORmediated suppression of phagophore formation [129-131]. The genetic increase in rab7 in $\mathrm{AD}[23,25]$ is somewhat inconsistent with this hypothetical lysosomal fusion failure, though it is possible that this upregulation is acting in an ineffective compensatory manner. However, it is interesting that late endosome marker rab24, but not secretory protein rab27, is upregulated in CA1 pyramidal neurons $[23,25]$ considering that GVD most greatly affects the CA1 region of the hippocampus [3]. This may reflect alternative responses to the disease process with one cell type opting for increased secretion and another for increased degradation to remove the toxic protein. 


\section{Conclusions}

We propose that lysosome fusion dysfunction is a candidate nidus for the major pathological hallmarks of $\mathrm{AD}$ including both defining lesions of AD, GVD bodies, as well as the presence of tau in the CSF. Although the origin of fusion dysfunction is not yet fully understood, it most likely results from the convergence of multiple factors, like the disease it manifests. The involvement of lysosomal dysfunction as an underlying and unifying hypothesis for AD pathology may change the overall view of AD pathogenesis. It provides novel insights into disease-associated mechanisms of protein misprocessing and potentially new modes of disease progression. There is also potential clinical importance of tau secretion biomarkers for CSF-based diagnostics and for the direction of future disease-modifying therapeutics.

\section{Abbreviations}

$\begin{array}{ll}\text { A } \beta: & \text { Amyloid beta } \\ \text { AD: } & \text { Alzheimer's disease } \\ \text { APP: } & \text { Amyloid precursor protein } \\ \text { BACE: } & \text { Beta secretase } \\ \text { CHMP2B: } & \text { Charged multivesicular body protein 2B } \\ \text { CSF: } & \text { Cerebrospinal fluid } \\ \text { e2, e3, e10: } & \text { Protein sequence encoded by exons 2, 3, } \\ & \text { 10, respectively } \\ \text { ESCRT: } & \text { Endosomal sorting complex required } \\ & \text { for transport } \\ \text { GVD: } & \text { Granulovacuolar degeneration } \\ \text { LC3: } & \text { Microtubule-associated protein 1 light } \\ & \text { chain 3 } \\ \text { MVB: } & \text { Multivesicular body } \\ \text { NFT: } & \text { Neurofibrillary tangle } \\ \text { PS1: } & \text { Presenilin 1 } \\ \text { p-tau: } & \text { Phosphorylated tau } \\ \text { PTM: } & \text { Posttranslational modification. }\end{array}$

\section{Acknowledgment}

This work was supported by an Award from the Public Health Service (AG14452).

\section{References}

[1] D. J. Selkoe, “The cell biology $\beta$-amyloid precursor protein and presenilin in Alzheimer's disease," Trends in Cell Biology, vol. 8, no. 11, pp. 447-453, 1998.

[2] M. Goedert, "Tau protein and the neurofibrillary pathology of Alzheimer's disease," Trends in Neurosciences, vol. 16, no. 11, pp. 460-465, 1993.

[3] M. J. Ball and P. Lo, "Granulovacuolar degeneration in the ageing brain and in dementia," Journal of Neuropathology and Experimental Neurology, vol. 36, no. 3, pp. 474-487, 1977.

[4] D. M. Holtzman, "CSF biomarkers for Alzheimer's disease: current utility and potential future use," Neurobiology of Aging, vol. 32, supplement 1, pp. S4-S9, 2011.

[5] A. Goate, M. C. Chartier-Harlin, M. Mullan et al., "Segregation of a missense mutation in the amyloid precursor protein gene with familial Alzheimer's disease," Nature, vol. 349, no. 6311, pp. 704-706, 1991.
[6] M. A. Smith, G. Perry, P. L. Richey et al., "Oxidative damage in Alzheimer's," Nature, vol. 382, no. 6587, pp. 120-121, 1996.

[7] T. Hasegawa, "Prolonged stress will induce Alzheimer's disease in elderly people by increased release of homocysteic acid," Medical Hypotheses, vol. 69, no. 5, pp. 1135-1139, 2007.

[8] I. Mellman, "Membranes and sorting," Current Opinion in Cell Biology, vol. 8, no. 4, pp. 497-498, 1996.

[9] A. V. Vieira, C. Lamaze, and S. L. Schmid, "Control of EGF receptor signaling by clathrin-mediated endocytosis," Science, vol. 274, no. 5295, pp. 2086-2089, 1996.

[10] P. A. Vanlandingham and B. P. Ceresa, "Rab7 regulates late endocytic trafficking downstream of multivesicular body biogenesis and cargo sequestration," The Journal of Biological Chemistry, vol. 284, no. 18, pp. 12110-12124, 2009.

[11] J. H. Hurley, "ESCRT complexes and the biogenesis of multivesicular bodies," Current Opinion in Cell Biology, vol. 20, no. 1, pp. 4-11, 2008.

[12] S. Saksena, J. Sun, T. Chu, and S. D. Emr, "ESCRTing proteins in the endocytic pathway," Trends in Biochemical Sciences, vol. 32, no. 12, pp. 561-573, 2007.

[13] R. L. Williams and S. Urbé, "The emerging shape of the ESCRT machinery," Nature Reviews Molecular Cell Biology, vol. 8, no. 5, pp. 355-368, 2007.

[14] R. M. Johnstone, A. Mathew, A. B. Mason, and K. Teng, "Exosome formation during maturation of mammalian and avian reticulocytes: evidence that exosome release is a major route for externalization of obsolete membrane proteins," Journal of Cellular Physiology, vol. 147, no. 1, pp. 27-36, 1991.

[15] C. Théry, L. Zitvogel, and S. Amigorena, "Exosomes: composition, biogenesis and function," Nature Reviews Immunology, vol. 2, no. 8, pp. 569-579, 2002.

[16] C. M. Fader and M. I. Colombo, "Autophagy and multivesicular bodies: two closely related partners," Cell Death and Differentiation, vol. 16, no. 1, pp. 70-78, 2009.

[17] S. Pankiv, T. H. Clausen, T. Lamark et al., "p62/SQSTM1 binds directly to Atg8/LC3 to facilitate degradation of ubiquitinated protein aggregates by autophagy," The Journal of Biological Chemistry, vol. 282, no. 33, pp. 24131-24145, 2007.

[18] Y. Kabeya, N. Mizushima, T. Ueno et al., "LC3, a mammalian homologue of yeast Apg8p, is localized in autophagosome membranes after processing," EMBO Journal, vol. 19, no. 21, pp. 5720-5728, 2000.

[19] W. A. Dunn Jr., "Studies on the mechanisms of autophagy: maturation of the autophagic vacuole," Journal of Cell Biology, vol. 110, no. 6, pp. 1935-1945, 1990.

[20] E. L. Eskelinen, "Maturation of autophagic vacuoles in Mammalian cells," Autophagy, vol. 1, no. 1, pp. 1-10, 2005.

[21] R. A. Nixon and A. M. Cataldo, "Lysosomal system pathways: genes to neurodegeneration in Alzheimer's disease," Journal of Alzheimer's Disease, vol. 9, no. 3, supplement, pp. 277-289, 2006.

[22] R. A. Nixon, P. M. Mathews, and A. M. Cataldo, "The neuronal endosomal-lysosomal system in Alzheimer's disease," Journal of Alzheimer's Disease, vol. 3, no. 1, pp. 97-107, 2001.

[23] S. D. Ginsberg, M. J. Alldred, S. E. Counts et al., "Microarray analysis of hippocampal CA1 neurons implicates early endosomal dysfunction during Alzheimer's disease progression," Biological Psychiatry, vol. 68, no. 10, pp. 885-893, 2010.

[24] S. D. Ginsberg, E. J. Mufson, S. E. Counts et al., "Regional selectivity of rab5 and rab7 protein upregulation in mild cognitive impairment and Alzheimer's disease," Journal of Alzheimer's Disease, vol. 22, no. 2, pp. 631-639, 2010. 
[25] S. D. Ginsberg, E. J. Mufson, M. J. Alldred et al., "Upregulation of select rab GTPases in cholinergic basal forebrain neurons in mild cognitive impairment and Alzheimer's disease," Journal of Chemical Neuroanatomy, vol. 42, no. 2, pp. 102-110, 2011.

[26] A. M. Cataldo, P. M. Mathews, A. B. Boiteau et al., "Down syndrome fibroblast model of Alzheimer-related endosome pathology: accelerated endocytosis promotes late endocytic defects," American Journal of Pathology, vol. 173, no. 2, pp. 370-384, 2008.

[27] A. M. Cataldo, C. M. Peterhoff, J. C. Troncoso, T. GomezIsla, B. T. Hyman, and R. A. Nixon, "Endocytic pathway abnormalities precede amyloid $\beta$ deposition in sporadic Alzheimer's disease and down syndrome: differential effects of APOE genotype and presenilin mutations," American Journal of Pathology, vol. 157, no. 1, pp. 277-286, 2000.

[28] Y. W. Zhang, R. Thompson, H. Zhang, and H. Xu, "APP processing in Alzheimer's disease," Molecular Brain, vol. 4, no. 1, article 3, 2011.

[29] V. Hook, T. Toneff, M. Bogyo et al., "Inhibition of cathepsin B reduces $\beta$-amyloid production in regulated secretory vesicles of neuronal chromaffin cells: evidence for cathepsin B as a candidate $\beta$-secretase of Alzheimer's disease," Biological Chemistry, vol. 386, no. 9, pp. 931-940, 2005.

[30] V. Y. H. Hook, M. Kindy, T. Reinheckel, C. Peters, and G. Hook, "Genetic cathepsin B deficiency reduces $\beta$-amyloid in transgenic mice expressing human wild-type amyloid precursor protein," Biochemical and Biophysical Research Communications, vol. 386, no. 2, pp. 284-288, 2009.

[31] I. Benilova, E. Karran, and B. De Strooper, "The toxic Abeta oligomer and Alzheimer's disease: an emperor in need of clothes," Nature Neuroscience, vol. 15, no. 3, pp. 349-357, 2012.

[32] D. Prvulovic and H. Hampel, "Amyloid $\beta(\mathrm{A} \beta)$ and phosphotau (p-tau) as diagnostic biomarkers in Alzheimer's disease," Clinical Chemistry and Laboratory Medicine, vol. 49, no. 3, pp. 367-374, 2011.

[33] A. M. Cataldo, J. L. Barnett, C. Pieroni, and R. A. Nixon, "Increased neuronal endocytosis and protease delivery to early endosomes in sporadic Alzheimer's disease: neuropathologic evidence for a mechanism of increased $\beta$ amyloidogenesis," Journal of Neuroscience, vol. 17, no. 16, pp. 6142-6151, 1997.

[34] A. M. Cataldo, S. Petanceska, N. B. Terio et al., "A $\beta$ localization in abnormal endosomes: association with earliest $\mathrm{A} \beta$ elevations in $\mathrm{AD}$ and Down syndrome," Neurobiology of Aging, vol. 25, no. 10, pp. 1263-1272, 2004.

[35] O. M. Grbovic, P. M. Mathews, Y. Jiang et al., "Rab5stimulated up-regulation of the endocytic pathway increases intracellular $\beta$-cleaved amyloid precursor protein carboxylterminal fragment levels and $\mathrm{A} \beta$ production," The Journal of Biological Chemistry, vol. 278, no. 33, pp. 31261-31268, 2003.

[36] P. M. Mathews, C. B. Guerra, Y. Jiang et al., "Alzheimer's disease-related overexpression of the cation-dependent mannose 6-phosphate receptor increases $\mathrm{A} \beta$ secretion: role for altered lysosomal hydrolase distribution in $\beta$-amyloidogenesis," The Journal of Biological Chemistry, vol. 277, no. 7, pp. 5299-5307, 2002.

[37] R. A. Nixon, A. M. Cataldo, and P. M. Mathews, "The endosomal-lysosomal system of neurons in Alzheimer's disease pathogenesis: a review," Neurochemical Research, vol. 25, no. 9-10, pp. 1161-1172, 2000.

[38] W. H. Yu, A. M. Cuervo, A. Kumar et al., "Macroautophagya novel $\beta$-amyloid peptide-generating pathway activated in
Alzheimer's disease," Journal of Cell Biology, vol. 171, no. 1, pp. 87-98, 2005.

[39] M. Arbel, I. Yacoby, and B. Solomon, "Inhibition of amyloid precursor protein processing by $\beta$-secretase through sitedirected antibodies," Proceedings of the National Academy of Sciences of the United States of America, vol. 102, no. 21, pp. 7718-7723, 2005.

[40] J. T. Huse, D. S. Pijak, G. J. Leslie, V. M. Y. Lee, and R. W. Doms, "Maturation and endosomal targeting of $\beta$-site amyloid precursor protein-cleaving enzyme. The Alzheimer's disease $\beta$-secretase," The Journal of Biological Chemistry, vol. 275, no. 43, pp. 33729-33737, 2000.

[41] S. Kametaka, M. Shibata, K. Moroe et al., "Identification of phospholipid scramblase 1 as a novel interacting molecule with $\beta$-secretase ( $\beta$-site amyloid precursor protein (APP) cleaving enzyme (BACE))," The Journal of Biological Chemistry, vol. 278, no. 17, pp. 15239-15245, 2003.

[42] A. Kinoshita, H. Fukumoto, T. Shah, C. M. Whelan, M. C. Irizarry, and B. T. Hyman, "Demonstration by FRET of BACE interaction with the amyloid precursor protein at the cell surface and in early endosomes," Journal of Cell Science, vol. 116, part 16, pp. 3339-3346, 2003.

[43] Y. H. Koh, C. A. F. von Arnim, B. T. Hyman, R. E. Tanzi, and G. Tesco, "BACE is degraded via the lysosomal pathway," The Journal of Biological Chemistry, vol. 280, no. 37, pp. 3249932504, 2005.

[44] R. P. Friedrich, K. Tepper, R. Rönicke et al., "Mechanism of amyloid plaque formation suggests an intracellular basis of A $\beta$ pathogenicity," Proceedings of the National Academy of Sciences of the United States of America, vol. 107, no. 5, pp. 1942-1947, 2010.

[45] E. H. Koo and S. L. Squazzo, "Evidence that production and release of amyloid $\beta$-protein involves the endocytic pathway," The Journal of Biological Chemistry, vol. 269, no. 26, pp. 17386-17389, 1994.

[46] L. McConlogue, F. Castellano, C. deWit, D. Schenk, and W. A. Maltese, "Differential effects of a Rab6 mutant on secretory versus amyloidogenic processing of Alzheimer's $\beta$-amyloid precursor protein," The Journal of Biological Chemistry, vol. 271, no. 3, pp. 1343-1348, 1996.

[47] G. D. Schellenberg and T. J. Montine, "The genetics and neuropathology of Alzheimer's disease," Acta Neuropathologica, vol. 124, no. 3, pp. 305-323, 2012.

[48] N. Takasugi, T. Tomita, I. Hayashi et al., "The role of presenilin cofactors in the $\gamma$-secratase complex," Nature, vol. 422, no. 6930, pp. 438-441, 2003.

[49] W. T. Kimberly, M. J. LaVoie, B. L. Ostaszewski, W. Ye, M. S. Wolfe, and D. J. Selkoe, " $\gamma$-Secretase is a membrane protein complex comprised of presenilin, nicastrin, aph-1, and pen2," Proceedings of the National Academy of Sciences of the United States of America, vol. 100, no. 11, pp. 6382-6387, 2003.

[50] P. Cupers, M. Bentahir, K. Craessaerts et al., "The discrepancy between presenilin subcellular localization and $\gamma$-secretase processing of amyloid precursor protein," Journal of Cell Biology, vol. 154, no. 4, pp. 731-740, 2001.

[51] D. M. Kovacs, H. J. Fausett, K. J. Page et al., "Alzheimerassociated presenilins 1 and 2: neuronal expression in brain and localization to intracellular membranes in mammalian cells," Nature Medicine, vol. 2, no. 2, pp. 224-229, 1996.

[52] D. Scheuner, C. Eckman, M. Jensen et al., "Secreted amyloid $\beta$-protein similar to that in the senile plaques of Alzheimer's disease is increased in vivo by the presenilin 1 and 2 and 
APP mutations linked to familial Alzheimer's disease," Nature Medicine, vol. 2, no. 8, pp. 864-870, 1996.

[53] D. R. Borchelt, G. Thinakaran, C. B. Eckman et al., "Familial Alzheimer's disease-linked presenilin I variants elevate a $\beta 1$ 42/1-40 ratio in vitro and in vivo," Neuron, vol. 17, no. 5, pp. 1005-1013, 1996.

[54] D. Cai, J. Y. Leem, J. P. Greenfield et al., "Presenilin-1 regulates intracellular trafficking and cell surface delivery of $\beta$-amyloid precursor protein," The Journal of Biological Chemistry, vol. 278, no. 5, pp. 3446-3454, 2003.

[55] C. Dumanchin, C. Czech, D. Campion et al., "Presenilins interact with Rab11, a small GTPase involved in the regulation of vesicular transport," Human Molecular Genetics, vol. 8, no. 7, pp. 1263-1269, 1999.

[56] W. Scheper, R. Zwart, and F. Baas, "Rab6 membrane association is dependent of Presenilin 1 and cellular phosphorylation events," Molecular Brain Research, vol. 122, no. 1, pp. 17-23, 2004.

[57] W. Scheper, R. Zwart, P. van der Sluijs, W. Annaert, W. A. van Gool, and F. Baas, "Alzheimer's presenilin 1 is a putative membrane receptor for rab GDP dissociation inhibitor," Human Molecular Genetics, vol. 9, no. 2, pp. 303-310, 2000.

[58] J. H. Lee, W. H. Yu, A. Kumar et al., "Lysosomal proteolysis and autophagy require presenilin 1 and are disrupted by Alzheimer-related PS1 mutations," Cell, vol. 141, no. 7, pp. 1146-1158, 2010.

[59] A. Yamamoto, Y. Tagawa, T. Yoshimori, Y. Moriyama, R. Masaki, and Y. Tashiro, "Bafilomycin A1 prevents maturation of autophagic vacuoles by inhibiting fusion between autophagosomes and lysosomes in rat hepatoma cell line, $\mathrm{H}$ 4-II-E cells," Cell Structure and Function, vol. 23, no. 1, pp. 33-42, 1998.

[60] X. Zhang, K. Garbett, K. Veeraraghavalu et al., "A role for presenilins in autophagy revisited: normal acidification of Lysosomes in cells lacking PSEN1 and PSEN2," Journal of Neuroscience, vol. 32, no. 25, pp. 8633-8648, 2012.

[61] K. Coen, R. S. Flannagan, S. Baron et al., "Lysosomal calcium homeostasis defects, not proton pump defects, cause endolysosomal dysfunction in PSEN-deficient cells," Journal of Cell Biology, vol. 198, no. 1, pp. 23-35, 2012.

[62] P. R. Pryor, B. M. Mullock, N. A. Bright, S. R. Gray, and J. P. Luzio, "The role of intraorganellar $\mathrm{Ca}^{2+}$ in late endosomelysosome heterotypic fusion and in the reformation of lysosomes from hybrid organelles," Journal of Cell Biology, vol. 149, no. 5, pp. 1053-1062, 2000.

[63] A. J. Morgan, F. M. Platt, E. Lloyd-Evans, and A. Galione, "Molecular mechanisms of endolysosomal $\mathrm{Ca}^{2+}$ signalling in health and disease," Biochemical Journal, vol. 439, no. 3, pp. 349-374, 2011.

[64] D. Harold, R. Abraham, P. Hollingworth et al., "Genomewide association study identifies variants at CLU and PICALM associated with Alzheimer's disease," Nature Genetics, vol. 41, no. 10, pp. 1088-1093, 2009.

[65] J. C. Lambert, S. Heath, G. Even et al., "Genome-wide association study identifies variants at CLU and CR1 associated with Alzheimer's disease," Nature Genetics, vol. 41, no. 10, pp. 1094-1099, 2009.

[66] R. W. Mahley and S. C. Rall Jr., "Apolipoprotein E: far more than a lipid transport protein," Annual Review of Genomics and Human Genetics, vol. 1, no. 2000, pp. 507-537, 2000.

[67] R. W. Mahley, K. H. Weisgraber, and Y. Huang, "Apolipoprotein E: structure determines function, from atherosclerosis to Alzheimer's disease to AIDS," Journal of Lipid Research, vol. 50, supplement, pp. S183-S188, 2009.
[68] E. Rogaeva, Y. Meng, J. H. Lee et al., "The neuronal sortilin-related receptor SORL1 is genetically associated with Alzheimer disease," Nature Genetics, vol. 39, no. 2, pp. 168$177,2007$.

[69] S. Seshadri, A. L. Fitzpatrick, M. A. Ikram et al., "Genomewide analysis of genetic loci associated with Alzheimer disease," The Journal of the American Medical Association, vol. 303, no. 18, pp. 1832-1840, 2010.

[70] L. Jones, D. Harold, and J. Williams, "Genetic evidence for the involvement of lipid metabolism in Alzheimer's disease," Biochimica et Biophysica Acta, vol. 1801, no. 8, pp. 754-761, 2010.

[71] T. Nuutinen, T. Suuronen, A. Kauppinen, and A. Salminen, "Clusterin: a forgotten player in Alzheimer's disease," Brain Research Reviews, vol. 61, no. 2, pp. 89-104, 2009.

[72] W. Kim, S. Lee, and G. F. Hall, "Secretion of human tau fragments resembling CSF-tau in Alzheimer's disease is modulated by the presence of the exon 2 insert," FEBS Letters, vol. 584, no. 14, pp. 3085-3088, 2010.

[73] W. Kim, S. Lee, C. Jung, A. Ahmed, G. Lee, and G. F. Hall, "Interneuronal transfer of human tau between lamprey central neurons in situ," Journal of Alzheimer's Disease, vol. 19, no. 2, pp. 647-664, 2010.

[74] E. Emmanouilidou, K. Melachroinou, T. Roumeliotis et al., "Cell-produced $\alpha$-synuclein is secreted in a calciumdependent manner by exosomes and impacts neuronal survival," Journal of Neuroscience, vol. 30, no. 20, pp. 68386851, 2010.

[75] B. Fevrier, D. Vilette, F. Archer et al., "Cells release prions in association with exosomes," Proceedings of the National Academy of Sciences of the United States of America, vol. 101, no. 26, pp. 9683-9688, 2004.

[76] L. Rajendran, M. Honsho, T. R. Zahn et al., "Alzheimer's disease $\beta$-amyloid peptides are released in association with exosomes," Proceedings of the National Academy of Sciences of the United States of America, vol. 103, no. 30, pp. 1117211177, 2006.

[77] S. Saman, W. Kim, M. Raya et al., "Exosome-associated tau is secreted in tauopathy models and is selectively phosphorylated in cerebrospinal fluid in early Alzheimer disease," The Journal of Biological Chemistry, vol. 287, no. 6, pp. 38423849, 2012.

[78] H. Braak, I. Alafuzoff, T. Arzberger, H. Kretzschmar, and K. Del Tredici, "Staging of Alzheimer disease-associated neurofibrillary pathology using paraffin sections and immunocytochemistry," Acta Neuropathologica, vol. 112, no. 4, pp. 389-404, 2006.

[79] S. Lee, W. Kim, Z. Li, and G. F. Hall, "Accumulation of vesicleassociated human tau in distal dendrites drives degeneration and tau secretion in an in situ cellular tauopathy model," International Journal of Alzheimer's Disease, vol. 2012, Article ID 172837, 16 pages, 2012.

[80] M. Sverdlov, A. N. Shajahan, and R. D. Minshall, "Tyrosine phosphorylation-dependence of caveolae-mediated endocytosis," Journal of Cellular and Molecular Medicine, vol. 11, no. 6, pp. 1239-1250, 2007.

[81] W. Nickel, "Unconventional secretory routes: direct protein export across the plasma membrane of mammalian cells," Traffic, vol. 6, no. 8, pp. 607-614, 2005.

[82] Y. Fang, N. Wu, X. Gan, W. Yan, J. C. Morrell, and S. J. Gould, "Higher-order oligomerization targets plasma membrane proteins and HIV gag to exosomes," PLoS Biology, vol. 5, no. 6, article e158, 2007. 
[83] P. J. Dolan and G. V. W. Johnson, "A caspase cleaved form of tau is preferentially degraded through the autophagy pathway," The Journal of Biological Chemistry, vol. 285, no. 29, pp. 21978-21987, 2010.

[84] R. A. Armstrong, N. J. Cairns, and P. L. Lantos, "Clustering of Pick bodies in patients with Pick's disease," Neuroscience Letters, vol. 242, no. 2, pp. 81-84, 1998.

[85] R. A. Armstrong, N. J. Cairns, and P. L. Lantos, "Clustering of cerebral cortical lesions in patients with corticobasal degeneration," Neuroscience Letters, vol. 268, no. 1, pp. 5-8, 1999.

[86] H. Braak and E. Braak, "Neuropathological stageing of Alzheimer-related changes," Acta Neuropathologica, vol. 82, no. 4, pp. 239-259, 1991.

[87] A. Gómez-Ramos, M. Díaz-Hernández, R. Cuadros, F. Hernández, and J. Avila, "Extracellular tau is toxic to neuronal cells," FEBS Letters, vol. 580, no. 20, pp. 4842-4850, 2006.

[88] A. Gómez-Ramos, M. Díaz-Hernández, A. Rubio, M. T. Miras-Portugal, and J. Avila, "Extracellular tau promotes intracellular calcium increase through M1 and M3 muscarinic receptors in neuronal cells," Molecular and Cellular Neuroscience, vol. 37, no. 4, pp. 673-681, 2008.

[89] K. Strauss, C. Goebel, H. Runz et al., "Exosome secretion ameliorates lysosomal storage of cholesterol in NiemannPick type C disease," The Journal of Biological Chemistry, vol. 285, no. 34, pp. 26279-26288, 2010.

[90] E. Bednarski and G. Lynch, "Cytosolic proteolysis of $\tau$ by cathepsin $\mathrm{D}$ in hippocampus following suppression of cathepsins B and L," Journal of Neurochemistry, vol. 67, no. 5, pp. 1846-1855, 1996.

[91] A. Kenessey, P. Nacharaju, L. W. Ko, and S. H. Yen, "Degradation of tau by lysosomal enzyme cathepsin D: implication for Alzheimer neurofibrillary degeneration," Journal of Neurochemistry, vol. 69, no. 5, pp. 2026-2038, 1997.

[92] J. Bendiske and B. A. Bahr, "Lysosomal activation is a compensatory response against protein accumulation and associated synaptopathogenesis-an approach for slowing Alzheimer disease?" Journal of Neuropathology and Experimental Neurology, vol. 62, no. 5, pp. 451-463, 2003.

[93] K. Ii, H. Ito, E. Kominami, and A. Hirano, "Abnormal distribution of cathepsin proteinases and endogenous inhibitors (cystatins) in the hippocampus of patients with Alzheimer's disease, parkinsonism-dementia complex on Guam, and senile dementia and in the aged," Virchows Archiv A, vol. 423, no. 3, pp. 185-194, 1993.

[94] K. Ikeda, H. Akiyama, T. Arai et al., "Alz-50/Gallyas-positive lysosome-like intraneuronal granules in Alzheimer's disease and control brains," Neuroscience Letters, vol. 258, no. 2, pp. 113-116, 1998.

[95] E. E. Congdon, S. Kim, J. Bonchak, T. Songrug, A. Matzavinos, and J. Kuret, "Nucleation-dependent tau filament formation: the importance of dimerization and an estimation of elementary rate constants," The Journal of Biological Chemistry, vol. 283, no. 20, pp. 13806-13816, 2008.

[96] Q. Zhong, E. E. Congdon, H. N. Nagaraja, and J. Kuret, “Tau isoform composition influences rate and extent of filament formation," The Journal of Biological Chemistry, vol. 287, no. 24, pp. 20711-20719, 2012.

[97] C. A. Dickey, A. Kamal, K. Lundgren et al., "The high-affinity HSP90-CHIP complex recognizes and selectively degrades phosphorylated tau client proteins," The Journal of Clinical Investigation, vol. 117, no. 3, pp. 648-658, 2007.
[98] W. Luo, F. Dou, A. Rodina et al., "Roles of heat-shock protein 90 in maintaining and facilitating the neurodegenerative phenotype in tauopathies," Proceedings of the National Academy of Sciences of the United States of America, vol. 104, no. 22, pp. 9511-9516, 2007.

[99] Y. Wang, M. Martinez-Vicente, U. Krüger et al., “Tau fragmentation, aggregation and clearance: the dual role of lysosomal processing," Human Molecular Genetics, vol. 18, no. 21, pp. 4153-4170, 2009.

[100] Y. P. Wang, J. Biernat, M. Pickhardt, E. Mandelkow, and E. M. Mandelkow, "Stepwise proteolysis liberates tau fragments that nucleate the Alzheimer-like aggregation of full-length tau in a neuronal cell model," Proceedings of the National Academy of Sciences of the United States of America, vol. 104, no. 24, pp. 10252-10257, 2007.

[101] A. Samsonov, J. Z. Yu, M. Rasenick, and S. V. Popov, "Tau interaction with microtubules in vivo," Journal of Cell Science, vol. 117, part 25, pp. 6129-6141, 2004.

[102] R. Dixit, J. L. Ross, Y. E. Goldman, and E. L. F. Holzbaur, "Differential regulation of dynein and kinesin motor proteins by tau," Science, vol. 319, no. 5866, pp. 1086-1089, 2008.

[103] L. C. Kapitein, M. A. Schlager, M. Kuijpers et al., "Mixed microtubules steer dynein-driven cargo transport into dendrites," Current Biology, vol. 20, no. 4, pp. 290-299, 2010.

[104] S. Love, L. R. Bridges, and C. P. Case, "Neurofibrillary tangles in Niemann-Pick disease type C," Brain, vol. 118, part 1, pp. 119-129, 1995.

[105] P. Z. Almos, S. Horvath, A. Czibula et al., "H1 tau haplotyperelated genomic variation at $17 \mathrm{q} 21.3$ as an Asian heritage of the European Gypsy population," Heredity, vol. 101, no. 5, pp. 416-419, 2008.

[106] R. L. Neve, P. Harris, K. S. Kosik, D. M. Kurnit, and T. A. Donlon, "Identification of cDNA clones for the human microtubule-associated protein tau and chromosomal localization of the genes for tau and microtubule-associated protein 2," Brain Research, vol. 387, no. 3, pp. 271-280, 1986.

[107] R. Brandt, J. Léger, and G. Lee, "Interaction of tau with the neural plasma membrane mediated by tau's amino-terminal projection domain," Journal of Cell Biology, vol. 131, no. 5, pp. 1327-1340, 1995.

[108] A. Abraha, N. Ghoshal, T. C. Gamblin et al., "C-terminal inhibition of tau assembly in vitro and in Alzheimer's disease," Journal of Cell Science, vol. 113, part 21, pp. 37373745, 2000.

[109] C. Haase, J. T. Stieler, T. Arendt, and M. Holzer, "Pseudophosphorylation of tau protein alters its ability for selfaggregation," Journal of Neurochemistry, vol. 88, no. 6, pp. 1509-1520, 2004.

[110] F. Liu, B. Li, E. J. Tung, I. Grundke-Iqbal, K. Iqbal, and C. $\mathrm{X}$. Gong, "Site-specific effects of tau phosphorylation on its microtubule assembly activity and self-aggregation," European Journal of Neuroscience, vol. 26, no. 12, pp. 3429-3436, 2007.

[111] H. Vanderstichele, K. De Vreese, K. Blennow et al., "Analytical performance and clinical utility of the INNOTEST PHOSPHO-TAU(181P) assay for discrimination between Alzheimer's disease and dementia with Lewy bodies," Clinical Chemistry and Laboratory Medicine, vol. 44, no. 12, pp. 14721480, 2006.

[112] D. H. Smith, D. F. Meaney, and W. H. Shull, "Diffuse axonal injury in head trauma," Journal of Head Trauma Rehabilitation, vol. 18, no. 4, pp. 307-316, 2003. 
[113] L. Buée, T. Bussière, V. Buée-Scherrer, A. Delacourte, and P. R. Hof, "Tau protein isoforms, phosphorylation and role in neurodegenerative disorders," Brain Research Reviews, vol. 33, no. 1, pp. 95-130, 2000.

[114] L. Martin, X. Latypova, and F. Terro, "Post-translational modifications of tau protein: implications for Alzheimer's disease," Neurochemistry International, vol. 58, no. 4, pp. 458$471,2011$.

[115] M. Morishima-Kawashima, M. Hasegawa, K. Takio, M. Suzuki, K. Titani, and Y. Ihara, "Ubiquitin is conjugated with amino-terminally processed tau in paired helical filaments," Neuron, vol. 10, no. 6, pp. 1151-1160, 1993.

[116] D. Cripps, S. N. Thomas, Y. Jeng, F. Yang, P. Davies, and A. J. Yang, "Alzheimer disease-specific conformation of hyperphosphorylated paired helical filament-Tau is polyubiquitinated through Lys-48, Lys-11, and Lys-6 ubiquitin conjugation," The Journal of Biological Chemistry, vol. 281, no. 16, pp. 10825-10838, 2006.

[117] S. N. Thomas, K. E. Funk, Y. Wan et al., "Dual modification of Alzheimer's disease PHF-tau protein by lysine methylation and ubiquitylation: a mass spectrometry approach," Acta Neuropathologica, vol. 123, no. 1, pp. 105-117, 2012.

[118] C. Raiborg, T. E. Rusten, and H. Stenmark, "Protein sorting into multivesicular endosomes," Current Opinion in Cell Biology, vol. 15, no. 4, pp. 446-455, 2003.

[119] V. Chau, J. W. Tobias, A. Bachmair et al., "A multiubiquitin chain is confined to specific lysine in a targeted short-lived protein," Science, vol. 243, no. 4898, pp. 1576-1583, 1989.

[120] T. J. Cohen, J. L. Guo, D. E. Hurtado et al., "The acetylation of tau inhibits its function and promotes pathological tau aggregation," Nature Communications, vol. 2, no. 1, article 252, 2011.

[121] S. W. Min, S. H. Cho, Y. Zhou et al., "Acetylation of tau inhibits its degradation and contributes to tauopathy," Neuron, vol. 67, no. 6, pp. 953-966, 2010.

[122] J. A. Latham and S. Y. R. Dent, "Cross-regulation of histone modifications," Nature Structural and Molecular Biology, vol. 14, no. 11, pp. 1017-1024, 2007.

[123] M. J. Ball, "Neuronal loss, neurofibrillary tangles and granulovacuolar degeneration in the hippocampus with ageing and dementia. A quantitative study," Acta Neuropathologica, vol. 37, no. 2, pp. 111-118, 1977.

[124] N. Ghoshal, F. García-Sierra, J. Wuu et al., "Tau conformational changes correspond to impairments of episodic memory in mild cognitive impairment and Alzheimer's disease," Experimental Neurology, vol. 177, no. 2, pp. 475493, 2002.

[125] K. Okamoto, S. Hirai, T. Iizuka, T. Yanagisawa, and M. Watanabe, "Reexamination of granulovacuolar degeneration," Acta Neuropathologica, vol. 82, no. 5, pp. 340-345, 1991.

[126] K. E. Funk, R. E. Mrak, and J. Kuret, "Granulovacuolar degeneration (GVD) bodies of Alzheimer's disease (AD) resemble late-stage autophagic organelles," Neuropathology and Applied Neurobiology, vol. 37, no. 3, pp. 295-306, 2011.

[127] Y. Yamazaki, T. Takahashi, M. Hiji et al., "Immunopositivity for ESCRT-III subunit CHMP2B in granulovacuolar degeneration of neurons in the Alzheimer's disease hippocampus," Neuroscience Letters, vol. 477, no. 2, pp. 86-90, 2010.

[128] B. Boland, A. Kumar, S. Lee et al., "Autophagy induction and autophagosome clearance in neurons: relationship to autophagic pathology in Alzheimer's disease," Journal of Neuroscience, vol. 28, no. 27, pp. 6926-6937, 2008.
[129] L. Q. Chen, J. S. Wei, Z. N. Lei, L. M. Zhang, Y. Liu, and F. Y. Sun, "Induction of Bcl-2 and Bax was related to hyperphosphorylation of tau and neuronal death induced by okadaic acid in rat brain," Anatomical Record A, vol. 287, no. 2, pp. 1236-1245, 2005.

[130] S. Díaz-Troya, M. E. Pérez-Pérez, F. J. Florencio, and J. L. Crespo, "The role of TOR in autophagy regulation from yeast to plants and mammals," Autophagy, vol. 4, no. 7, pp. 851865, 2008.

[131] G. A. Soliman, H. A. Acosta-Jaquez, E. A. Dunlop et al., "mTOR Ser-2481 autophosphorylation monitors mTORCspecific catalytic activity and clarifies rapamycin mechanism of action," The Journal of Biological Chemistry, vol. 285, no. 11, pp. 7866-7879, 2010. 


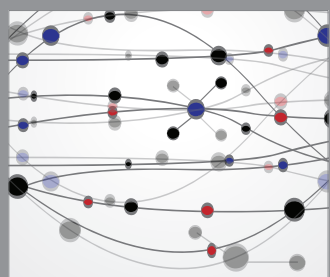

The Scientific World Journal
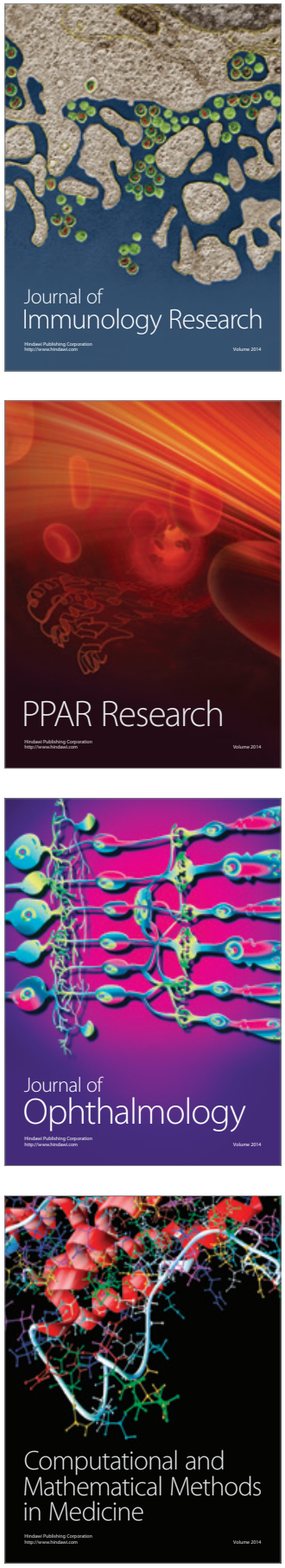

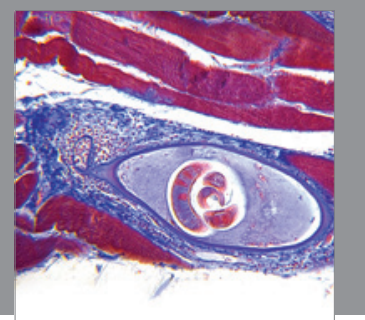

Gastroenterology

Research and Practice
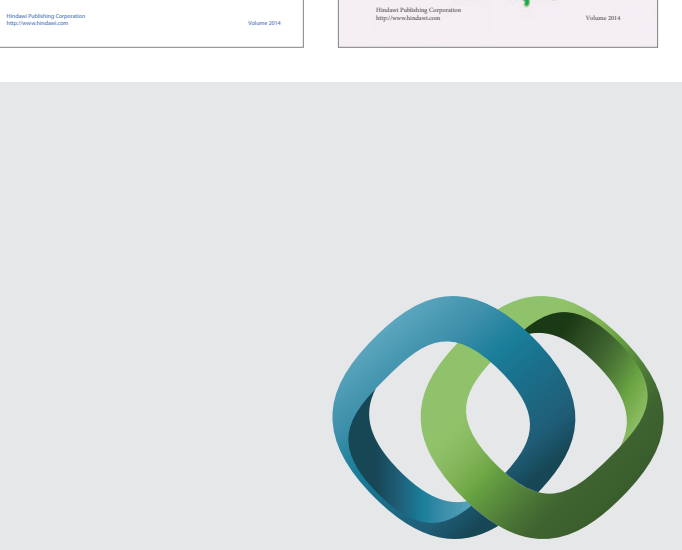

\section{Hindawi}

Submit your manuscripts at

http://www.hindawi.com
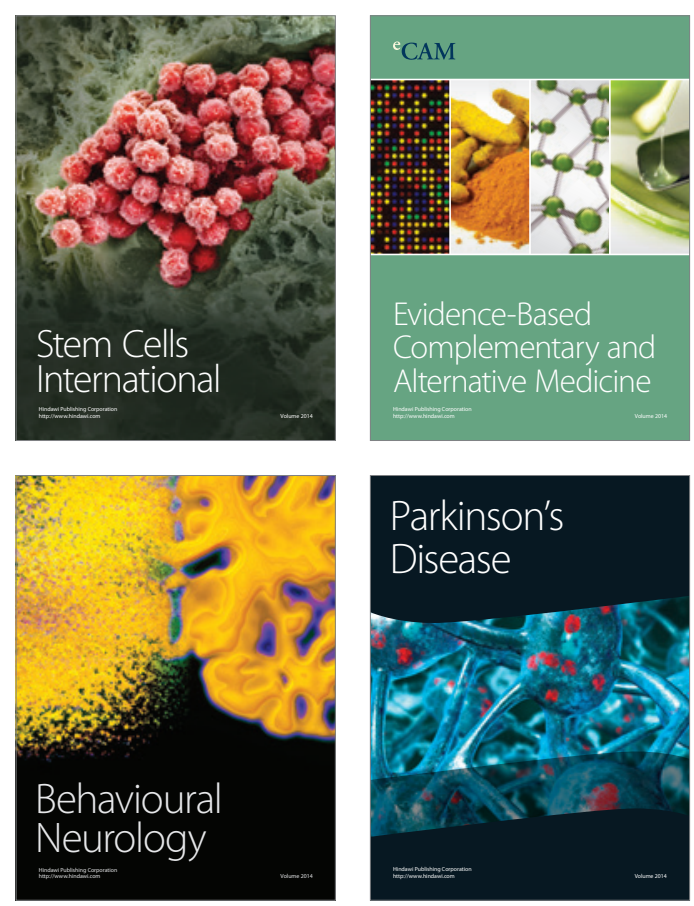

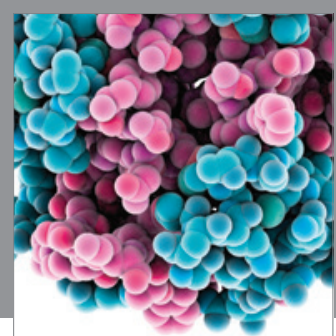

Journal of
Diabetes Research

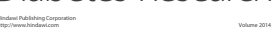

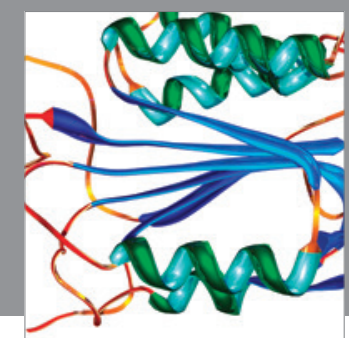

Disease Markers
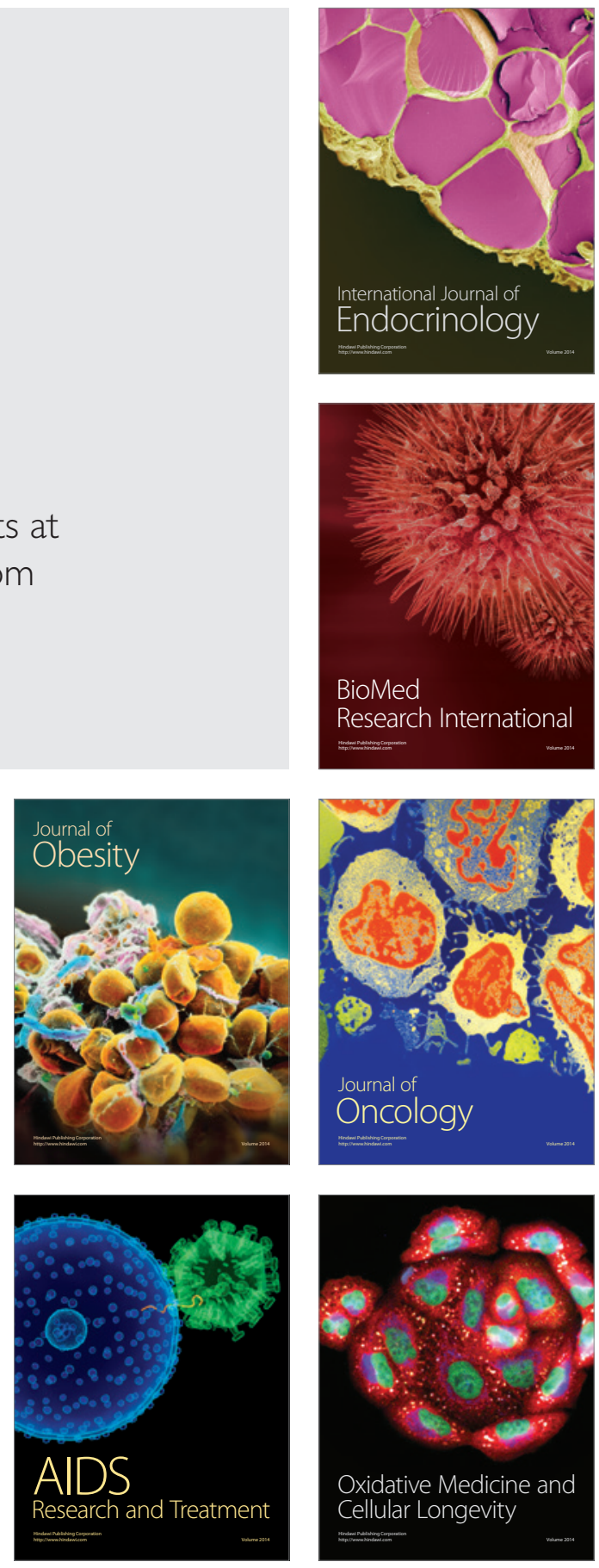